\title{
Diagnostic characterization of acute promyelocytic leukemia and targeted therapy in this leukemia
}

\begin{abstract}
Acute promyelocytic leukemia (APL) was first described as an entity in1957 in Norway and is characterized by a translocation between the promyelocytic leukemia gene (PML) on chromosome 15 and the retinoic acid receptor-alpha (RAR-alpha) gene on chromosome 17, has become a model for targeted treatment of cancer. Advances in our understanding of the fundamental biology of this disease have led to the development of tools for diagnosis, monitoring of minimal residual disease, and detection of early relapse. Differentiation therapy with all-trans retinoic acid in combination with chemotherapy has significantly improved survival in patients with APL. Moreover, arsenic trioxide, which induces differentiation and apoptosis of APL cells, has become standard treatment for relapsed disease, and its role in the treatment of newly diagnosed APL is under active investigation.
\end{abstract}

Volume 5 Issue I - 2017

\author{
Saeed Nasouhi pur \\ Department of Hematology, Tabriz University of medical \\ sciences, Iran
}

\begin{abstract}
Correspondence: Saeed Nasouhi pur, Dept of Hematology, Faculty of pirapezeshki, Tabriz university of medical sciences, Iran, Email snasouhipur|33I@gmail.com
\end{abstract}

Received: October 25, 2016 | Published: July 13, 2017

Keywords: pro-coagulant, multi-lobed nuclei, NuMA-RARa, PLZF, CD2

Abbreviations: APL, acute promyelocytic leukemia; PML, promyelocytic leukemia gene; RAR-a, retinoic acid receptor-alpha; AML, acute myeloid leukemia; DIC, disseminated intravascular coagulation; AMOL, acute monocytic leukemia; HDAC, histone deacetylases; ATRA, all-trans retinoic acid; WBC, white blood cell count

\section{Introduction}

This type of acute promyelocytic leukemia (APL) is a unique subtype of Acute Myeloid Leukemia (AML) which is characterized either by abnormal promyelocytes with distinctive large granules and multiple Auer rods (faggots or sultan bodies cells) or, less commonly, by atypical hypo-granular or micro-granular cells with bilobed or multi-lobed nuclei. ${ }^{1,2}$ These cells contain pro-coagulant material which, when released into the circulation, causes disseminated intravascular coagulation (DIC). Excessive bleeding due to DIC is common. The micro-granular variant of APL may be mistaken with acute monocytic leukemia (AMOL). In the micro-granular variant M3, only occasional cells have granules visible by light microscopy, so morphology and immunophenotyping is suggested for diagnosis of this variant M3. The promyelocytic gene (PML) is encoded by the long arm of chromosome 15 and is expressed ubiquitously. ${ }^{3}$ PML is thought to be involved in apoptosis and tumor suppression. The cytogenetic documents of $\mathrm{t}(15 ; 17)$, and FISH is required for confirmation of diagnosis. The translocation $\mathrm{t}(15 ; 17)$ ( $\mathrm{q} 22 ; \mathrm{q} 21)$ or $\mathrm{t}(15 ; 17)(\mathrm{q} 22, \mathrm{q} 11-12)$ is the genetic hallmark of APL, resulting in the PML-RARa fusion protein. There are three possible isoforms caused by PML-RARa translocations. ${ }^{4}$ The breakpoint in chromosome 17 is consistently found in intron 2, but varies in chromosome 15 . The three breakpoints on the PML gene can occur at intron 3(L form), intron 6 ( $\mathrm{S}$ form), and exon 6 ( $\mathrm{V}$ form). The $\mathrm{S}$ form is reportedly associated with a shorter remission duration and overall survival compared with the L form. PML-RARa Recruits histone deacetylases (HDAC) and represses target genes of wild type RARa leading to a block of myeloid differentiation. The Retinoic Acid Receptor a_ (RARa_) Chimeric proteins PML-, PLZF-, NPM-, and NuMA-RARa_ have distinct Intracellular Localization Patterns. NPM-RARa is predominantly nuclear whereas NuMA-RARa _ is predominantly cytoplasmic. Typical immunophenotypic findings in APL: CD34. HLA-DR and Tdt usually is negative and CD2 is expression in a minority. This leukemia with $\mathrm{t}(15 ; 17)$ has a good prognosis, because it is sensitive to retinoid and chemotherapy, whereas PLZF-RARa Consistent with this, APL patients bearing the $\mathrm{t}(11 ; 17)(\mathrm{q} 23 ; \mathrm{q} 21)$ respond poorly to ATRA treatment. ATRA was introduced clinically in 1985, and this opened a new era in the treatment of APL. ATRA induces differentiation of leukemic promyelocytes into mature granulocytes. All-trans retinoic acid (ATRA) as a highly effective therapy in acute promyelocytic leukemia (APL) The patients receiving ATRA followed by chemotherapy did significantly better compared with patients treated with ATRA alone or chemotherapy alone. ${ }^{5}$ With this combination the CR rate ranges from 90 to 96 percent.

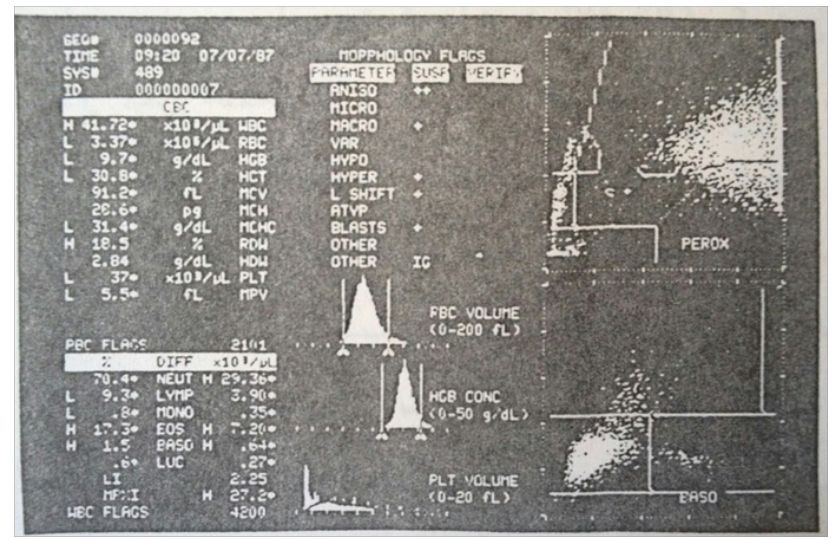

Figure I Peripheral blood of a patient with Acute promyelocytic Leukemia (M3). In Bayer $\mathrm{H}-\mathrm{I}$ series instrument, on the peroxidase cytogram, all the peroxidase positive cells appear well over to the right in a fan shape (triangularity). The leukocyte count may either be decreased or very high, thrombocytopeny is Severe with anemia. MPXI is greatly increased $(H)$. 


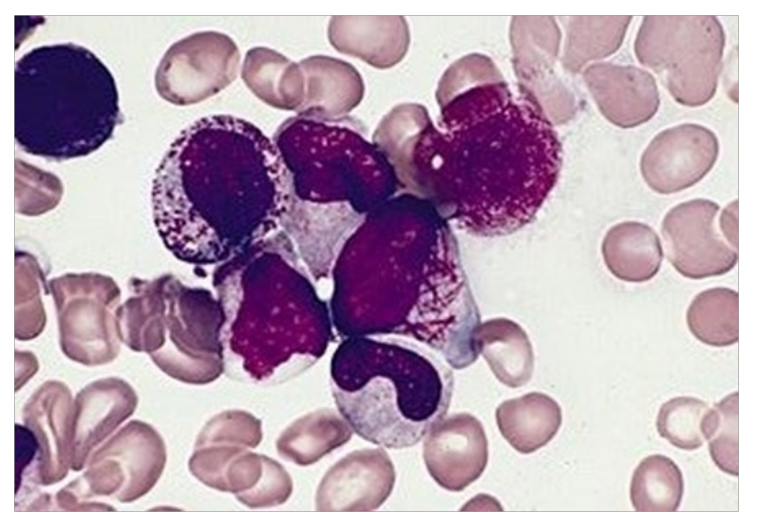

Figure 2 On smear study the predominant immature-or blastic cells are abnormal promyelocytes and also may be numerous (around $10 \%$ ) metamyelocyte. A faggot cell (Middle right) content numerous Auer rods in the cytoplasm of a malignant promyelocyte from a patient with acute promyelocytic leukemia, M3 (hypergranular).

\section{Conclusion}

Risk stratification is imperative in the treatment of APL patients, as those with low-risk disease (white blood cell count (WBC) $\leq 10000 / \mu \mathrm{l})$ are generally treated with less intensive regimens than those patients presenting with high-risk disease (WBC $>10000 / \mu 1)$. Treatment options for patients with relapsed disease include arsenic trioxide and allogeneic stem cell transplant.

\section{Acknowledgements}

None.

\section{Conflict of interest}

The author declares no conflict of interest.

\section{References}

1. Hoffbrand AV, Pettit JE. Clinical hematology illustrated an integrated text and colour atlas. 1st ed. Gower Medical Publishing, USA: WB Saunders Company; 1990.

2. Barbara J Bain. Blood Cells: A practical Guide. 3rd ed. USA: WileyBlackwell; 2000. 160 p.

3. Mary LTurgeon. Clinical Hematology-Theory and Procedures. 5th ed. USA: MT(ASCP); 2012. p. 632.

4. Jurcic JG, Soignet SL, Maslak AP. Diagnosis an treatment of acute promyelocytic leukemia. Curr Oncol Rep. 2007;9(5):337-344.

5. Sanz MA. Treatment of Acute promyelocytic leukemia. Hematology Am Soc Hematol Educ Program. 2006;2006:147-155.

6. Coombs CC, Tavakkoli M, Tallman MS. Acute promyelocytic leukemia: where did we start, where are we now, and the future. Blood Cancer J. 2015;5:e304.

7. Prébet T, Gore SD, Esterni B, et al. Outcome of high-risk myelodysplastic syndrome after azacitidine treatment failure. $J$ Clin Oncol. 2011;29(24):3322-3327. 